\title{
Hypoxia and chronic lung disease
}

\author{
Rubin M. Tuder • Jeong H. Yun • Anil Bhunia • \\ Iwona Fijalkowska
}

Received: 1 October 2007 / Revised: 23 October 2007 / Accepted: 24 October 2007 / Published online: 27 November 2007

(C) Springer-Verlag 2007

\begin{abstract}
The lung is both the conduit for oxygen uptake and is also affected by hypoxia and hypoxia signaling. Decreased ventilatory drive, airway obstructive processes, intra-alveolar exudates, septal thickening by edema, inflammation, fibrosis, or damage to alveolar capillaries will all interpose a significant and potentially life-threatening barrier to proper oxygenation, therefore enhancing the alveolar/arterial $\mathrm{pO}_{2}$ gradient. These processes result in decreased blood and tissue oxygenation. This review addresses the relationship of hypoxia with lung development and with lung diseases. We particularly focus on molecular mechanisms underlying hypoxia-driven physiological and pathophysiological lung processes, specifically in the infant lung, pulmonary hypertension, and chronic obstructive pulmonary disease.
\end{abstract}

\footnotetext{
R. M. Tuder $(\bowtie) \cdot J$. H. Yun • A. Bhunia • I. Fijalkowska

Division of Cardiopulmonary Pathology,

Department of Pathology,

Johns Hopkins University School of Medicine,

720 Rutland Avenue, Ross Research Building, Room 519,

Baltimore, MD 21205, USA

e-mail: RTuder@jhmi.edu

J. H. Yun

e-mail: JYUN@JSPH.EDU
}

A. Bhunia

e-mail: ABHUNIA@JHMI.EDU

I. Fijalkowska

e-mail: IFIJALK1@JHMI.EDU

R. M. Tuder

Division of Pulmonary and Critical Care Medicine,

Department of Medicine,

Johns Hopkins University School of Medicine,

Baltimore, MD, USA
Keywords Hypoxia · Lung · Pathology $\cdot$ HIF

Air, containing oxygen at approximately $21 \%$ partial pressure at sea level $(140-150 \mathrm{mmHg})$, travels through up to 20 generations of airways by mass flow and then diffuses into the gas exchange units (alveoli) in the lung with a partial pressure of approximately $105-110 \mathrm{mmHg}$. The human lung contains approximately 480 million alveoli, which represent $64 \%$ of total lung structure. These alveoli are elegantly packed in only 1.3-2.6 $\mathrm{L}$ of total lung volume, providing a surface area of $120-150 \mathrm{~m}^{2}$, equivalent to the dimensions of a "tennis court" dedicated for gas exchange. Although the molecular determinants of lung size are not known, oxygen diffusion constant and gas exchange surface area are roughly proportional to body weight and oxygen consumption in different species [1]. Physical hyperactivity and exposure to a cold environment or high altitude lead to increased oxygen diffusion capacity, in proportion to enhanced oxygen consumption [1].

Decreased ventilatory drive, airway obstructive processes, intraalveolar exudates, septal thickening by edema, inflammation, fibrosis, or damage to alveolar capillaries will all interpose a significant and potentially life-threatening barrier to proper oxygenation, therefore enhancing the alveolar/ arterial $\mathrm{pO}_{2}$ gradient. This review addresses the contribution of hypoxia to lung diseases and the potential molecular mechanisms involved in hypoxia-driven physiological and pathophysiological lung processes (Fig. 1), particularly in the infant lung, pulmonary hypertension, and chronic obstructive pulmonary disease. The fundamental concepts underlying hypoxia-induced gene expression and the molecular regulation of $\mathrm{HIF}(\mathrm{s})$ also apply to the lung, and they will be cited in relation to their demonstrated role in lung physiology or pathophysiology. 


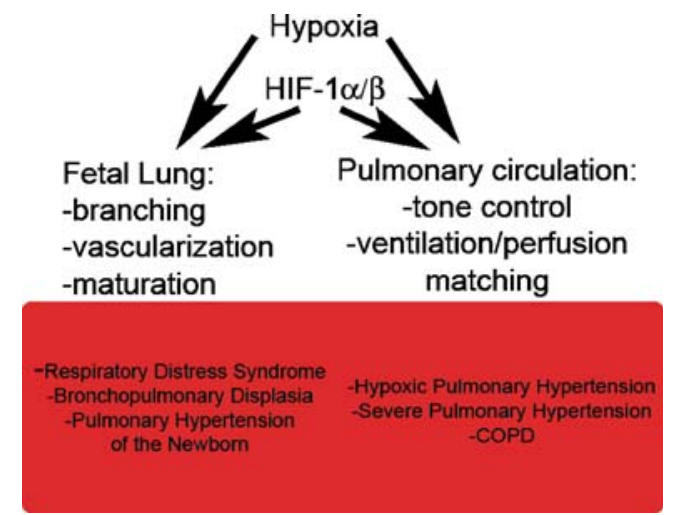

Fig. 1 Summary of effects of hypoxia and/or HIF-1/2 $\alpha$ in lung homeostasis and disease (box)

\section{Hypoxia signaling in the lung}

Hypoxia-inducible factor-HIF- $1 \alpha$ and HIF- $2 \alpha$ probably regulate the expression of most of hypoxia-dependent and many hypoxia-independent genes involved lung homeostasis and disease. Hypoxia triggers several additional signaling mechanisms, many of which interface with HIF-dependent signaling. Under hypoxia, the reduction of energy production has a major negative impact on the translational rate of proteins, as hypoxia and HIF- $1 \alpha$ inhibit mTOR signaling, a critical signaling pathway involved in the induction of cell growth and protein synthesis [2].

Recent evidence indicates that hypoxia induces the synthesis of microRNAs (MIRs), which add additional levels of complexity in the regulation of gene expression under hypoxia [3, 4]. MIRs, a group of small RNAs with approximately 22 nucleotides in length, have important roles in the regulation of gene expression. MIRs posttranscriptionally regulate gene expression by forming perfect base pairing with sequences in the $3^{\prime}$ untranslated region ( $3^{\prime}$ UTR) of genes, resulting in enhanced mRNA degradation, while imperfect matching may lead to repressed or inefficient mRNA translation. More than 500 MIRs have been identified in the mammalian genome so far. In a recent survey of MIRs induced or downregulated by hypoxia, several of hypoxia MIRs shared HIF-binding sequences in regulatory regions [4]. Of note, some of these MIRs protect against apoptosis [4]. A set of MIRs modulate the hypoxic expression of vascular endothelial growth factor (VEGF) expression and other angiogenic factors [5]. Other studies have shown that hypoxia-responsive transcription factors such as NF-kB and p53 induce MIRs [6]. Although the investigation of hypoxic MIRs has been restricted to screenings in cell cultures and in silico comparison with tumor data sets [4], the list of MIRs present in the hypoxic lung has not been compiled thus far. Nevertheless, the first evidence that MIRs may participate in lung diseases was provided by the report that MIR-155 might regulate inflammatory cell responses, such as in asthma [7].

During hypoxia, EGR-1, a zinc-finger transcription factor expressed in monocytes, leads to the production of tissue factor and fibrin deposition in the pulmonary vasculature [8]. In mice lung subjected to hypoxia, EGR-1 and tissue factor are coproduced in bronchial and vascular smooth muscle cells and alveolar macrophages [9]. Thus, hypoxia-induced EGR-1 activity accelerates pulmonary vascular thrombosis.

\section{Hypoxia, lung development and growth, and respiratory distress syndrome}

The lung develops in relative hypoxic conditions in utero as the fetus is exposed to approximately $25 \%$ of ambient oxygen levels [10]. In line with the evidence that the hypoxic fetal environment stimulates embryonic development [11], organogenesis, and organ-specific vascularization [12], the effect of hypoxia on lung development seems to reside on the stimulation of branching morphogenesis and the coordinated growth and development of a closely integrated pulmonary arterial blood supply. In vitro studies have shown that fetal oxygen tension enhances epithelial and vascular branching of mouse lung and maintains lung morphogenesis in rats [13]. Terminal branching of trachea is regulated by local oxygen tension, as hypoxia stimulates Bnl FGF, a growth factor that induces tracheal sprouting, while high oxygen tension suppresses terminal branching [14].

The expression of VEGF, a potent inducer of vasculogenesis in the lung, relies largely on HIF-1/2 $\alpha$ [15]. Indeed, human fetal lung explants cultured at physiological oxygen tension levels (i.e., about $40 \mathrm{mmHg}$ ) have increased VEGF compared with explants cultured at normoxic condition [16, 17]. Fetal VEGF is involved in lung development, as inhibition of VEGF receptor signaling impairs airway and blood vessel branching in lung explants [18].

Loss of function experiments in rodents highlighted the critical role of molecular control of hypoxia and particularly of HIF in lung growth and maturation. Deletion of HIF- $1 \alpha$ decreases branching morphogenesis and vascularization [19]. Deletion of HIF-2 $\alpha$ delays lung maturation in a VEGF-dependent manner, leading to pulmonary distress and fatality in knockdown pups. Both the alveolar epithelial and vascular systems show signs of significant immaturity, which resembles the lung complications of prematurity in humans [20].

Proper lung development requires a tight regulation of expression levels of $\operatorname{HIF}(\mathrm{s})$ and hypoxia-inducible genes, such as VEGF. Chemical stabilization of HIF-1 $\alpha$ due to prolyl-4-hydroxylase (PHD) inhibition with $\mathrm{CoCl}_{2}$ or dexferrioxamine interrupts airway and vascular branching 
in cultured fetal lung explants or causes hypervascularity with the nonspecific PHD inhibition with dimethyloxalylglycine [18]. Moreover, lung overexpression of VEGF through fetal development also leads to a hypervascular lung [21].

As a corollary of these data, HIF- $1 \alpha$ may also regulate fetal to neonatal transition and postnatal lung growth and repair as suggested by the fact that, in the absence of hypoxia, normal postnatal and post-pneumectomized regenerative lungs have increased HIF- $1 \alpha$ expression for months after surgery [22].

Impairment of lung growth is a major factor limiting survival of preterm babies. Immature pulmonary surfactant protein predisposes preterm babies to develop respiratory distress syndrome (RDS), characterized by decreased lung compliance and impaired gas exchange leading to hypoxia. Oxygen therapy to treat RDS exposes these infants to oxidative injury, which may impair the expression of growth factors (i.e., VEGF) involved in vascular and alveolar development, therefore leading to bronchopulmonary dysplasia (BPD) [23]. The potential role of the HIF/VEGF axis in fetal lung maturation lung was demonstrated in HIF- $2 \alpha$ knockout mice that are born with lung immaturity and show a phenotype similar to respiratory distress syndrome (RDS). RDS predisposes to BPD, whose pathogenesis resembles, to some extent, that of retinopathy of prematurity, in which high oxygen levels lead to disruption of VEGF-maintenance of blood vessels and endothelial cell apoptosis, resulting in organ damage. In fact, the expression of HIF- $1 \alpha$, HIF- $2 \alpha$, and downstream angiogenic growth factors (VEGF, PECAM-1, Flt-1, and Tie-2) are decreased in animal models of RDS or BPD [24-27]. Several of adolescent and adult BPD patients exhibit an emphysematous phenotype, potentially related to disruption of alveolar maintenance (see emphysema, below). The findings that PHDs control HIF degradation under normoxia and PHD activity is increased with increased oxygen availability [28] have offered new opportunities to develop therapies for BPD, as HIF- $1 \alpha$ stabilization with PHD inhibitors improves lung growth and oxygenation [29].

\section{Hypoxia, pulmonary circulation, and pulmonary hypertension}

Overall, the pulmonary vasculature comprises approximately one-third of estimated total number of 1 to $6 \times 10^{13}$ endothelial cells in the human body (covering an area equivalent to $1,200-2,500 \mathrm{~m}^{2}$ ). The pulmonary endothelium actively participates in hypoxia-induced responses, integrating sensing and effector functions that transmit changes in blood flow and vascular pressure. Injury or dysfunction of endothelium induced by hypoxia leads to increased perme- ability, heightened vascular smooth muscle tone, enhanced thrombotic state, and cell proliferation, all of which participate in the process of tissue remodeling.

Acute decreases in inspired (alveolar) oxygen to levels below $12 \%$ of normal (approximately equivalent to an altitude of $18,000 \mathrm{ft}$ ) induce reversible constriction of vascular pulmonary smooth muscle cells (PASMCs), a unique property of pre-acinar pulmonary arteries present across most mammals, reptiles, birds, and fish [30-32]. This contraction constitutes hypoxic pulmonary vasoconstriction (HPV), i.e., a rise of $4-8 \mathrm{mmHg}$ in pulmonary arterial pressures with decreased inspired oxygen. Experimentally, hypoxia triggers a biphasic pressure response, an early one followed by vasorelaxation and a persistent second wave of contraction; this second stage may represent the true basis of HPV. Teleologically, HPV serves to allow for matching between ventilation and perfusion, diverting blood flow from hypoxic to better aerated alveoli. The multidetector-row computer tomography (MR-CT) has permitted functional lung studies, such as the documentation of HPV in real time by imaging regional pulmonary blood flow and ventilation [33]. Interestingly, bacterial infection or lipopolysaccharide inhibit HPV, which can be visualized and documented by MR-CT (Fig. 2, based on [33]). Oxygen sensing in PASMCs has been attributed to: (1) mitochondrial respiration, (2) mitochondria-dependent decreases in reactive oxygen species (ROS), (3) mitochondriadependent increases in ROS, (4) mitochondria membrane depolarization, (5) decreased ATP levels with generation of cyclic ADP-ribose, (6) NADPH oxidase, (7) small GTPase RhoA-mediated sensitization to intracellular $\mathrm{Ca}^{+2}$, and (8) cytochrome $P 450$-mediated activation of hemoxygenase- 2 [32].

High altitude pulmonary edema (HAPE) is characterized by shortness of breath that increases with altitude ascent without a period of acclimatization. It occurs in $0.1-15 \%$ individuals, pending individual susceptibility and preexisting cardiovascular diseases [34]. HAPE is associated with marked increases of pulmonary artery pressures caused by $\mathrm{HPV}$, in excess of 35 to $40 \mathrm{mmHg}$. However, HPV is not uniform in the lung. Alveolar fluid leak with the potential complication of alveolar hemorrhage may result from a focally reduced HPV, leading to increased blood flow and disruption of the alveolar-capillary barrier. The main hypotheses to explain HAPE lie on excessive vasoconstriction, excessive inflammation due to hypoxia, or downregulation of alveolar cell ion pumps that move sodium and fluid from alveoli into the blood stream [34]. As mice exposed to chronic hypoxia develop lung inflammation [35], it is conceivable that acute hypoxia may trigger acute lung inflammation. However, acute inflammation and HPV may not coexist, as inflammation caused by lipopolysaccharide prevents HPV (Fig. 2) [36]. 
a
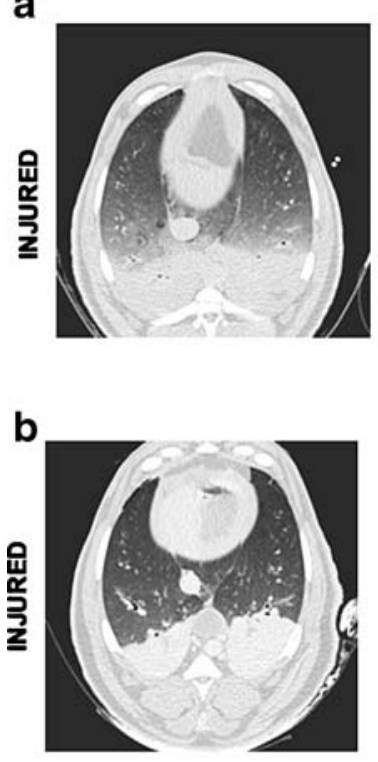

Saline Injured
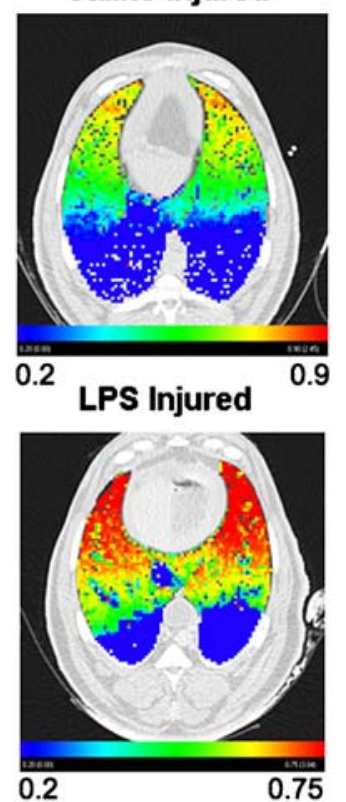
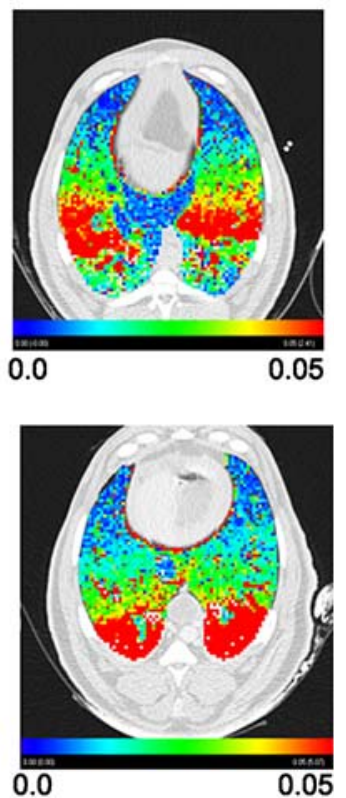

Fig. 2 Documentation of HPV by multidetector-row CT. a Salineinjured dog lung (in supine position, with nondependent areas at 12 o'clock and dependent regions at 6 o'clock) showing lung edema and atelectasis in the dependent areas (whitened areas in the left upper panel), with reduced aeration (digital quantification expressed as blue pixels in upper middle panel). This poorly aerated dependent region also shows markedly decreased blood flow (i.e., more blue/green

Chronic hypoxia causes pulmonary hypertension $(\mathrm{PH})$, which consists of an increase in mean pulmonary artery pressures in excess of $25 \mathrm{mmHg}$ at rest or $30 \mathrm{mmHg}$ on exercise [37]. Hypoxia-induced PH is usually mild (i.e., less than $45 \mathrm{mmHg}$ ) and potentially reversible upon normalization of inspired oxygen levels. PH associated pixels in upper right panel) due to HPV. Normally, these dependent areas should receive most of the pulmonary blood flow. b LPS instillation causes loss of HPV, when the poorly aerated dependent flooded areas (blue pixels in lower middle panel) have preferential pulmonary blood flow (red pixels in lower right panel) (based on [33], reprinted under permission)

with several lung diseases, particularly with sleep apnea and potentially with chronic obstructive pulmonary diseases (COPD), has been linked to chronic hypoxia. The experimental model of hypoxia-induced $\mathrm{PH}$ is based on exposure of rodents to $50 \%$ reduced oxygen levels for more than 2 weeks. This model is characterized by vascular cell
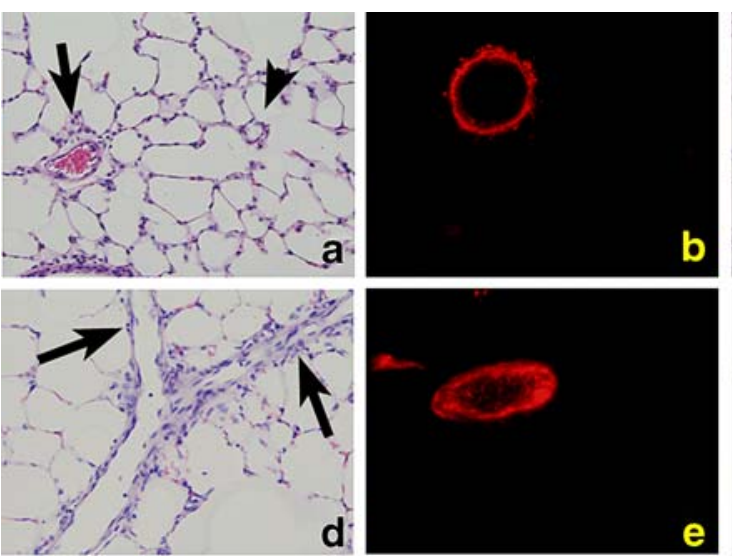

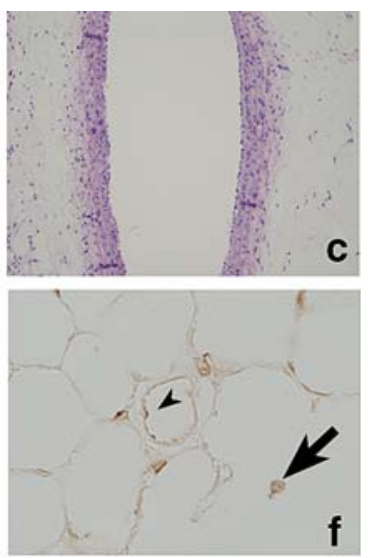

C.

artery of rats exposed to chronic hypoxia, showing prominent medial layer. d Extension of medial muscular layer towards the lung periphery of a pulmonary artery sectioned longitudinally. e Immunofluorescence with an anti-smooth muscle $\alpha$-actin antibody highlights increased medial thickness of a chronically hypoxic pulmonary artery. f Hydroxyprobe-based detection of cellular hypoxia, showing staining of endothelial cells in pulmonary arteries (arrowhead) and of type II epithelial cells (arrow) in lungs exposed to chronic hypoxia 
proliferation, involving initially endothelial cells, followed by PASMCs, and then adventitial fibroblasts [38]. Increased medial thickness becomes apparent with 2 weeks of chronic hypoxia exposure (Fig. 3). Hypoxia stimulates a wide array of potential mediators of PASMC growth, including platelet-derived growth factor, transforming growth factor $\beta$, and NADP oxidase subunit 4. Although there is no evidence that humans living in high altitude or suffering from lung diseases associated with chronic hypoxia are at increased risk of severe PH (i.e., pulmonary artery pressures in excess of $45 \mathrm{mmHg}$ ), investigation of the underlying mechanisms involving hypoxia sensing have offered new insights in the pathogenesis of the human disease.

Pulmonary endothelial cell dysfunction, a leading concept of the pathogenesis of PH [39], may account for excessive pulmonary vascular cell growth and/or decreased cell death [40]. An extension of this paradigm is the evidence that the pulmonary vascular remodeling in severe $\mathrm{PH}$ involves elements of abnormal angiogenesis [40], and it resembles that seen in neoplastic cells [41]. HIF-1 $\alpha$ controls several features involved in angiogenesis and cancer cell growth, including mitochondria function, which have been validated recently in studies of experimental PH [42]. Mitochondria of PASMCs are different from their systemic counterpart, as they have lower respiratory rates, are more depolarized, have more manganese superoxide dismutase (MnSOD), and produce more hydrogen peroxide [43]. Under normoxic conditions, the electron transport in mitochondria results in a small production of superoxide radicals, in proportion to alveolar oxygen pressure. Superoxide, a potentially toxic reactive oxygen species (ROS), is converted to a hydrogen peroxide that acts as diffusible second messenger and subsequently regulates activity of redox-sensitive transcription factors, including HIF- $1 \alpha$, and the activation and expression of voltage-gated $\mathrm{K}_{\mathrm{v}}{ }^{+}$channels (e.g., $\mathrm{K}_{\mathrm{v}}^{+}{ }^{+} 1.5$ ). There has been an intense debate whether hypoxic pulmonary vascular cells have increased or decreased oxidative stress. However, one view predicates that, within seconds of exposure to hypoxia, mitochondrial ROS production decreases, which inhibits oxygen-sensitive $\mathrm{K}_{\mathrm{v}}^{+}$channels and causes membrane depolarization, activation of voltage-gated L-type calcium channels, and calcium influx, thereby initiating HPV [44]. If this redox oxygen sensor is impaired, disrupted mitochondria create a false "hypoxic signal", chronically activating HIF- $1 \alpha$ under normoxic conditions. HIF- $1 \alpha$ activation downregulates oxygen-sensitive $\mathrm{K}_{\mathrm{v}}^{+}$channels $\left(\mathrm{K}_{\mathrm{v}}^{+1.5}\right)$ and initiates a cascade that causes PH. This mechanism has been postulated to lead not only to enhanced vasoconstriction, but also to resistance to cell death via hyperpolarization of mitochondria and enhanced survivin expression [45].

The involvement of HIF- $1 \alpha$ in PH was documented by the finding that heterozygous mice when exposed to hypoxia $\left(10 \% \quad \mathrm{O}_{2}\right.$ for 1 to 6 weeks) developed less polycythemia, right ventricular hypertrophy, pulmonary hypertension, pulmonary vascular remodeling, and weight loss than wild-type mice [46]. HIF-2 $\alpha$, which is abundantly expressed in the lung, is also involved in $\mathrm{PH}$, in that heterozygous mice are fully protected against $\mathrm{PH}$ and right ventricular hypertrophy caused by chronic hypoxia [47]. HIF- $1 \alpha$ regulates PASMC $\mathrm{K}_{\mathrm{v}}^{+}$capacitance, $\mathrm{K}^{+}$current density, and membrane depolarization, which are decreased in HIF- $1 \alpha_{-}^{+}{ }^{+-}$cells [48]. After exposure to chronic hypoxia, wild-type PASMCs increase the expression and activity of $\mathrm{Na}^{+} / \mathrm{H}^{+}$exchanger (NHE), which results in increased intracellular $\mathrm{pH}$ and cell growth [49]. Recent reports indicate that hypoxic PASMCs have increased expression of canonical transient receptor potential (TRPC) channels 1 and 6 in a HIF-1 $\alpha$-dependent manner [50].

There is experimental and clinical data that implicate serotonin in $\mathrm{PH}$ and lung hypoxic responses. Serotonin (5-HT) could affect pulmonary vascular remodeling, as it promotes vasoconstriction and vascular smooth muscle cell growth [51]. Hypoxia modifies plasma levels of serotonin, serotonin transporter activity, and expression of $5-\mathrm{HT}_{1 \mathrm{~B}}$ and 5-HR $2 \mathrm{~B}$ receptors [52]. However, rather than 5-HT transporters, serotonin receptors might instead mediate hypoxic $\mathrm{PH}$ as demonstrated by the protection against hypoxic $\mathrm{PH}$ documented in mice lacking $5-\mathrm{HT}_{2 \mathrm{~B}}$ receptors [53].

Under physiological conditions, endothelial cells remain quiescent and slow growing with only 1 dividing cell per 10,000 cells at any given time, which translates into a rate of one cellular division every 2 weeks. In severe pulmonary arterial hypertension (PAH), there is a unique and characteristic presence of plexiform lesions in the lumens of medium and small precapillary pulmonary arteries. These lesions show enhanced expression of VEGF, VEGF receptor, HIF- $1 \alpha$, and HIF- $1 \beta$, which suggests that lesions may develop by a process of disordered angiogenesis [54]. Similar results were recently obtained with cultured endothelial cells isolated form patients with IPAH. These cells have greater proliferation rate and decreased apoptosis, higher level of phosphorylated STAT3 and increased expression of its downstream prosurvival target, Mcl-1 [55]. Moreover, endothelial cells from idiopathic PAH lungs have decreased mitochondria and use preferentially the glycolytic pathway to generate energy, properties in common to cancer cells [56]. Although the involvement of HIF in this phenotype and in disease severity has not yet been formally tested, it is conceivable that vascular cells have an altered hypoxia-sensing mechanism, predisposing them to increased growth potential and even genomic instability. In a model of severe $\mathrm{PH}$ in the rat, chronic hypoxia in association with chronic VEGF receptor inhibition with SU5416 may be critically involved in the initial endothelial cell death and selection of apoptosis- 
resistant proliferating cells, which obliterate the pulmonary arteries [57].

Mutations of bone morphogenetic protein receptor 2 (BMPR-2) are involved in approximately $60 \%$ of the familial cases of familial PAH. Up to the present day, it is not clear how the germ line mutation in a single copy of the gene causes IPAH. There is evidence that either a state of haploinsufficiency or dominant negative effects leads to enhanced growth of cultured IPAH PASMCs. Although BMPR-2 heterozygous mice have normal lungs and pulmonary circulation at baseline, they develop more pronounced $\mathrm{PH}$ (though of mild severity) under inflammatory conditions or under hypoxia [58].

\section{Hypoxia and chronic obstructive pulmonary diseases}

COPD is the fourth leading cause of morbidity and mortality in the United States alone [59]. This syndrome is mostly caused by chronic cigarette smoke inhalation and exposure to environmental pollutants. In COPD, progressive airflow limitation and destruction of the alveolar capillary network may lead to decreased oxygen transport and alveolar hypoxia.

The finding that blockade of VEGF receptor signaling causes rodent emphysema led to several studies that documented decreased VEGF and VEGF receptor expression in emphysematous lungs [60]. Whether the expression of HIF and other signaling molecules involved in hypoxia sensing is abnormal in emphysema remains unknown. There is recent evidence that cigarette smoke impairs HIF- $1 \alpha$ expression in ischemic limbs of mice, causing decreased revascularization [61]. Moreover, we found that RTP-801 or Redd-1, a negative regulator of mTOR signaling and hypoxia-responsive gene product, is induced by cigarette smoke. RTP801 knockout mice were significantly resistant to cigarette smoke-induced inflammation and emphysema [62]. About $60 \%$ of patients with COPD suffer from mild $\mathrm{PH}$. Up to $5 \%$ of COPD patients have severe levels of $\mathrm{PH}$ with pulmonary artery pressures similar to that found in the systemic circulation [63]. PH in COPD is not fully explained by hypoxia alone, as it occurs in nonhypoxic patients and long-term oxygen therapy or nitric oxide inhalation do not reverse the pulmonary vascular changes. A direct toxic effect of cigarette smoke on pulmonary vasculature has been suggested to act in concert with a potential hypoxic effect observed in COPD [63].

\section{Conclusions}

Cellular signaling involved in hypoxia sensing participates in several physiological and pathophysiological processes in the lung. Several of these effects can be traced to availability of oxygen itself, as long-term oxygen therapy is the only proven effective therapy that increases long-term survival for patients in COPD [64]. Hypoxia itself or hypoxia-induced signaling may underlie the pathogenesis of several life-threatening lung diseases, as it regulates the expression of several critical genes. Lessons learned in the role of hypoxia in tumor growth and organ biology will certainly apply to fundamental aspects of lung repair, cell injury, or inflammation. We are just the beginning of the systematic exploration of this paradigm in pulmonary diseases. These efforts will translate in a better understanding of hypoxia-driven cell signaling and of suitability of therapeutic targets aimed at several lung diseases, including lung immaturity, pulmonary hypertension, and COPD.

Acknowledgements The authors thank Shehzin Mozammel and Reda Girgis for providing the immunofluorescence images and Dr. Brett Simon for the documentation of MR-CT, Ms. Amy Richter for the hydroxyprobe staining, and Mrs. Kathleen Wolfe for the secretarial support.

Grant support This work has been supported by the CMREF Center for Tissue Processing Center of the Pulmonary Hypertension Breakthrough Initiative, P150 HL 084946-01 (Pathology Core and Project 5), and HL 66554.

\section{References}

1. Weibel ER (1980) Design and structure of human lung in Pulmonary diseases and disorders. McGrow-Hill Book Company, New York

2. Liu L, Cash TP, Jones RG, Keith B, Thompson CB, Simon MC (2006) Hypoxia-induced energy stress regulates mRNA translation and cell growth. Mol Cell 4:521-531

3. Kulshreshtha R, Ferracin M, Negrini M, Calin GA, Davuluri RV, Ivan M (2007) Regulation of microRNA expression: the hypoxic component. Cell Cycle 12:1426-1431

4. Kulshreshtha R, Ferracin M, Wojcik SE, Garzon R, Alder H, gosto-Perez FJ, Davuluri R, Liu CG, Croce CM, Negrini M, Calin GA, Ivan M (2007) A microRNA signature of hypoxia. Mol Cell Biol 5:1859-1867

5. Arbiser JL, Klauber N, Rohan RM, van Leeuwen R, Huang MT, Fisher C, Flynn E, Byers HR (1998) Curcumin is an in vivo inhibitor of angiogenesis. Mol Med 6:376

6. Kent OA, Mendell JT (2006) A small piece in the cancer puzzle: microRNAs as tumor suppressors and oncogenes. Oncogene 46:6188-6196

7. Rodriguez A, Vigorito E, Clare S, Warren MV, Couttet P, Soond DR, van DS, Grocock RJ, Das PP, Miska EA, Vetrie D, Okkenhaug K, Enright AJ, Dougan G, Turner M, Bradley A (2007) Requirement of bic/microRNA-155 for normal immune function. Science 5824: 608-611

8. Yan SF, Zou YS, Gao Y, Zhai C, Mackman N, Lee SL, Mibrandt J, Pinsky D, Kisiel W, Stern D (1998) Tissue factor transcription driven by Egr-1 is a critical mechanism of murine pulmonary fibrin deposition in hypoxia. Proc Natl Acad Sci USA 14:8298

9. Lawson CA, Yan SD, Yan SF, Liao H, Zhou YS, Sobel J, Kisiel W, Stern DM, Pinsky DJ (1997) Monocytes and tissue factor promote 
thrombosis in a murine model of oxygen deprivation. J Clin Invest 7:1729-1738

10. van Tuyl M, Liu J, Wang J, Kuliszewski M, Tibboel D, Post M (2005) Role of oxygen and vascular development in epithelial branching morphogenesis of the developing mouse lung. Am J Physiol Lung Cell Mol Physiol 1:L167-L178

11. Maltepe E, Simon MC (1998) Oxygen, genes, and development: an analysis of the role of hypoxic gene regulation during murine vascular development. J Mol Med 6:391-401

12. Tufro-McReddie A, Norwood VF, Aylor KW, Botkin SJ, Carey RM, Gomez RA (1997) Oxygen regulates vascular endothelial growth factor-mediated vasculogenesis and tubulogenesis. Dev Biol $2: 139-149$

13. Gebb SA, Jones PL (2003) Hypoxia and lung branching morphogenesis. Adv Exp Med Biol 28:133-137

14. Jarecki J, Johnson E, Krasnow MA (1999) Oxygen regulation of airway branching in Drosophila is mediated by branchless FGF. Cell 2:211-220

15. Minchenko A, Bauer T, Salceda S, Caro J (1994) Hypoxic stimulation of vascular endothelial growth factor expression in vitro and in vivo. Lab Invest 3:374-379

16. Jakkula M, Le Cras TD, Gebb S, Hirth KP, Tuder RM, Voelkel NF, Abman SH (2000) Inhibition of angiogenesis decreases alveolarization in the developing rat lung. Am J Physiol, Lung Cell Mol Physiol 3:L600-L607

17. Acarregui MJ, Snyder JM, Mendelson CR (1993) Oxygen modulates the differentiation of human fetal lung in vitro and its responsiveness to cAMP. Am J Physiol Lung Cell Mol Physiol 5: L465-L474

18. Groenman FA, Rutter M, Wang J, Caniggia I, Tibboel D, Post M (2007) Effect of chemical stabilizers of hypoxia-inducible factors on early lung development. Am J Physiol Lung Cell Mol Physiol 3:L557-L567

19. van Tuyl M, Liu J, Wang J, Kuliszewski M, Tibboel D, Post M (2005) Role of oxygen and vascular development in epithelial branching morphogenesis of the developing mouse lung. Am J Physiol Lung Cell Mol Physiol 1:L167-L178

20. Compernolle V, Brusselmans K, Acker T, Hoet P, Tjwa M, Beck H, Plaisance S, Dor Y, Keshet E, Lupu F, Nemery B, Dewerchin M, Van Veldhoven P, Plate K, Moons L, Collen D, Carmeliet P (2002) Loss of HIF-2alpha and inhibition of VEGF impair fetal lung maturation, whereas treatment with VEGF prevents fatal respiratory distress in premature mice. Nat Med 7:702-710

21. Zeng X, Wert SE, Federici R, Peters KG, Whitsett JA (1998) VEGF enhances pulmonary vasculogenesis and disrupts lung morphogenesis. Dev Dyn 211:215-227

22. Zhang Q, Moe OW, Garcia JA, Hsia CCW (2006) Regulated expression of hypoxia-inducible factors during postnatal and postpneumonectomy lung growth. Am J Physiol Lung Cell Mol Physiol 5:L880-L889

23. Asikainen TM, White CW (2005) Antioxidant defenses in the preterm lung: role for hypoxia-inducible factors in BPD. Toxicol Appl Pharmacol 2:177-188

24. Grover TR, Asikainen TM, Kinsella JP, Abman SH, White CW (2007) Hypoxia-inducible factors HIF-1alpha and HIF-2alpha are decreased in an experimental model of severe respiratory distress syndrome in preterm lambs. Am J Physiol Lung Cell Mol Physiol 6:L1345-L1351

25. Lassus P, Turanlahti M, Heikkila P, Andersson LC, Nupponen I, Sarnesto A, Andersson S (2001) Pulmonary vascular endothelial growth factor and Flt-1 in fetuses, in acute and chronic lung disease, and in persistent pulmonary hypertension of the newborn. Am J Respir Crit Care Med 10 Pt 1:1981-1987

26. Bhatt AJ, Pryhuber GS, Huyck H, Watkins RH, Metlay LA, Maniscalco WM (2001) Disrupted pulmonary vasculature and decreased vascular endothelial growth factor, Flt-1, and TIE-2 in human infants dying with bronchopulmonary dysplasia. Am J Respir Crit Care Med 10 Pt 1:1971-1980

27. Maniscalco WM, Watkins RH, Pryhuber GS, Bhatt A, Shea C, Huyck H (2002) Angiogenic factors and alveolar vasculature: development and alterations by injury in very premature baboons. Am J Physiol Lung Cell Mol Physiol 4:L811-L823

28. Asikainen TM, Ahmad A, Schneider BK, Ho WB, Arend M, Brenner M, Gunzler V, White CW (2005) Stimulation of HIF1alpha, HIF-2alpha, and VEGF by prolyl 4-hydroxylase inhibition in human lung endothelial and epithelial cells. Free Radic Biol Med 8:1002-1013

29. Asikainen TM, Chang LY, Coalson JJ, Schneider BK, Waleh NS, Ikegami M, Shannon JM, Winter VT, Grubb P, Clyman RI, Yoder BA, Crapo JD, White CW (2006) Improved lung growth and function through hypoxia-inducible factor in primate chronic lung disease of prematurity. FASEB J 10:1698-1700

30. von Euler US, Liljsjestrand G (1946) Observations of the pulmonary arterial blood pressure on the cat. Acta Physiol Scand $12: 301-320$

31. Weissmann N, Sommer N, Schermuly RT, Ghofrani HA, Seeger W, Grimminger F (2006) Oxygen sensors in hypoxic pulmonary vasoconstriction. Cardiovasc Res 4:620-629

32. Ghofrani HA, Voswinckel R, Reichenberger F, Weissmann N, Schermuly RT, Seeger W, Grimminger F (2006) Hypoxia- and non-hypoxia-related pulmonary hypertension-established and new therapies. Cardiovasc Res 1:30-40

33. Easley RB, Fuld MK, Fernandez-Bustamante A, Hoffman EA, Simon BA (2006) Mechanism of hypoxemia in acute lung injury evaluated by multidetector-row CT. Acad Radiol 7:916921

34. Swenson ER (2006) Hypoxic lung whiteout: further clearing but more questions from on high. Ann Intern Med 7:550-552

35. Minamino T, Christou H, Hsieh CM, Li Y, Dhawan V, Abraham NJ, Perrella MA, Mitsialis SA, Kourembanas S (2001) Targeted expression of hemeoxygenase-1 prevents the pulmonary inflammatory and vascular responses to hypoxia. Proc Natl Acad Sci USA 15:8798-8803

36. Hoffman EA, Simon BA, McLennan G (2006) State of the art. A structural and functional assessment of the lung via multidetectorrow computed tomography: phenotyping chronic obstructive pulmonary disease. Proc Am Thorac Soc 6:519-532

37. Voelkel NF, Tuder RM (2000) Hypoxia-induced pulmonary vascular remodeling - a model for what human disease. J Clin Invest 6:733-738

38. Meyrick B, Reid L (1979) Hypoxia and incorporation of 3Hthymidine by cells of the rat pulmonary arteries and alveolar wall. Am J Pathol 1:51-70

39. Budhiraja R, Tuder RM, Hassoun PM (2004) Endothelial dysfunction in pulmonary hypertension. Circulation 2:159-165

40. Zaiman A, Fijalkowska I, Hassoun PM, Tuder RM (2005) One hundred years of research in the pathogenesis of pulmonary hypertension. Am J Respir Cell Mol Biol 5:425-431

41. Voelkel NF, Cool CD, Lee SD, Wright L, Geraci MW, Tuder RM (1999) Primary pulmonary hypertension between inflammation and cancer. Chest Suppl 3:225S-230S

42. Bonnet S, Michelakis ED, Porter CJ, Andrade-Navarro MA, Thebaud B, Bonnet S, Haromy A, Harry G, Moudgil R, McMurtry MS, Weir EK, Archer SL (2006) An abnormal mitochondrial-hypoxia inducible factor-1alpha-Kv channel pathway disrupts oxygen sensing and triggers pulmonary arterial hypertension in fawn hooded rats: similarities to human pulmonary arterial hypertension. Circulation 22:2630-2641

43. Michelakis ED, Hampl V, Nsair A, Wu X, Harry G, Haromy A, Gurtu R, Archer SL (2002) Diversity in mitochondrial function explains differences in vascular oxygen sensing. Circulation Research 12:1307-1315 
44. Reeve HL, Archer SL, Weir EK (1997) Ion channels in the pulmonary vasculature. Pulm Pharmacol Ther 10:243-252

45. McMurtry MS, Archer SL, Altieri DC, Bonnet S, Haromy A, Harry G, Bonnet S, Puttagunta L, Michelakis ED (2005) Gene therapy targeting survivin selectively induces pulmonary vascular apoptosis and reverses pulmonary arterial hypertension. J Clin Invest 6:1479-1491

46. Yu AY, Shimoda LA, Iyer NV, Huso DL, Sun X, McWilliams R, Beaty T, Sham JS, Wiener CM, Sylvester JT, Semenza GL (1999) Impaired physiological responses to chronic hypoxia in mice partially deficient for hypoxia-inducible factor 1 alpha. J Clin Invest 5:691-696

47. Brusselmans K, Compernolle V, Tjwa M, Wiesener MS, Maxwell PH, Collen D, Carmeliet P (2003) Heterozygous deficiency of hypoxiainducible factor-2alpha protects mice against pulmonary hypertension and right ventricular dysfunction during prolonged hypoxia. J Clin Invest 10:1519-1527

48. Shimoda LA, Manalo DJ, Sham JSK, Semenza GL, Sylvester JT (2001) Partial HIF-1 \{alpha\} deficiency impairs pulmonary arterial myocyte electrophysiological responses to hypoxia. Am J Physiol, Lung Cell Mol Physiol 1:L202-L208

49. Shimoda LA, Fallon M, Pisarcik S, Wang J, Semenza GL (2006) HIF-1 regulates hypoxic induction of NHE1 expression and alkalinization of intracellular $\mathrm{pH}$ in pulmonary arterial myocytes. Am J Physiol, Lung Cell Mol Physiol 5:L941-L949

50. Wang J, Weigand L, Lu W, Sylvester JT, Semenza L, Shimoda LA (2006) Hypoxia inducible factor 1 mediates hypoxia-induced TRPC expression and elevated intracellular $\mathrm{Ca}^{2+}$ in pulmonary arterial smooth muscle cells. Circ Res 12:1528-1537

51. Fanburg BL, Lee SL (2000) A role for the serotonin transporter in hypoxia-induced pulmonary hypertension. J Clin Invest 11:1521-1523

52. Eddahibi S, Hanoun N, Lanfumey L, Lesch KP, Raffestin B, Hamon M, Adnot S (2000) Attenuated hypoxic pulmonary hypertension in mice lacking the 5-hydroxytryptamine transporter gene. J Clin Invest 11:1555-1562

53. Launay JM, Herve P, Peoc'h K, Tournois C, Callebert J, Nebigil CG, Etienne N, Drouet L, Humbert M, Simonneau G, Maroteaux L (2002) Function of the serotonin 5-hydroxytryptamine 2B receptor in pulmonary hypertension. Nat Med 10:1129-1135

54. Tuder RM, Chacon M, Alger L, Wang J, Taraseviciene-Stewart L, Kasahara Y, Cool CD, Bishop AE, Geraci M, Semenza GL, Yacoub M, Polak JM, Voelkel NF (2001) Expression of angiogenesis-related molecules in plexiform lesions in severe pulmonary hypertension: evidence for a process of disordered angiogenesis. J Pathol 3:367-374

55. Masri FA, Xu W, Comhair SAA, Asosingh K, Koo M, Vasanji A, Drazba J, Anand-Apte B, Erzurum SC (2007) Hyperproliferative apoptosis-resistant endothelial cells in idiopathic pulmonary arterial hypertension. Am J Physiol, Lung Cell Mol Physiol 3:L548-L554

56. Xu W, Koeck T, Lara AR, Neumann D, DiFilippo FP, Koo M, Janocha AJ, Masri FA, Arroliga AC, Jennings C, Dweik RA, Tuder RM, Stuehr DJ, Erzurum SC (2007) Alterations of cellular bioenergetics in pulmonary artery endothelial cells. Proc Natl Acad Sci USA 4:1342-1347

57. Taraseviciene-Stewart L, Kasahara Y, Alger L, Hirth P, Mc Mahon GG, Waltenberger J, Voelkel NF, Tuder RM (2001) Inhibition of the VEGF receptor 2 combined with chronic hypoxia causes cell death-dependent pulmonary endothelial cell proliferation and severe pulmonary hypertension. Faseb J 2:427-438

58. Beppu H, Ichinose F, Kawai N, Jones RC, Yu PB, Zapol WM, Miyazono K, Li E, Bloch KD (2004) BMPR-II heterozygous mice have mild pulmonary hypertension and an impaired pulmonary vascular remodeling response to prolonged hypoxia. Amer J Physiol -Lung Cell M PH 6:L1241-L1247

59. Yoshida T, Tuder RM (2007) Pathobiology of cigarette smokeinduced chronic obstructive pulmonary disease. Physiol Rev 3:1047-1082

60. Voelkel NF, Vandivier RW, Tuder RM (2006) Vascular endothelial growth factor in the lung. Am J Physiol Lung Cell Mol Physiol 2: L209-L221

61. Michaud SE, Menard C, Guy LG, Gennaro G, Rivard A (2003) Inhibition of hypoxia-induced angiogenesis by cigarette smoke exposure: impairment of the HIF-1alpha/VEGF pathway. Faseb J 9:1150-1152

62. Yoshida T, Rangasamy T, Biswal S, Petrache I, Mett I, Feinstein E, Tuder RM (2006) Role of RTP801, a suppressor of the mTOR pathway, in cigarette smoke-induced pulmonary injury in mice. Proc Am Thorac Soc 6:551a-552a

63. Wright JL, Levy RD, Churg A (2005) Pulmonary hypertension in chronic obstructive pulmonary disease: current theories of pathogenesis and their implications for treatment. Thorax 7:605-609

64. Croxton TL, Bailey WC, for the NHLBI Working Group on Longterm Oxygen Treatment in COPD (2006) Long-term oxygen treatment in chronic obstructive pulmonary disease: recommendations for future research: An NHLBI Workshop Report. Am J Respir Crit Care Med 4(373-378) 